\title{
Mathematics And Experiential Learning - Are They Compatible?
}

Nitza Davidovitch, Ariel University, Israel

Roman Yavich, Ariel University, Israel

Nelly Keller, Ariel University, Israel

\begin{abstract}
In the process of experiential learning, students acquire skills and values as the consequence of a direct experience. Experiential learning draws on senses, emotions, and cognition and appeals to learners' entire being. Such learning, by nature, enables the development of a variety of capabilities, such as planning, teamwork, coping with stressful situations, responsibility, and leadership. Experiential learning has many different definitions; it is referred to here as a "sequence of events that include one or more specific study objects requiring active involvement of learners in various stages of the process" (Walter \& Marks, 1981, p. 1). This definition perceives the process of experiential learning as an active practice in which learners leave the conventional situation of mediated learning in favor of unmediated learning through practice. Experiential learning is based mainly on the behavioral-cognitive approach, which contends that change on the cognitive level might occur amidst an experience and project onto behavioral and emotional aspects as well. In the current article, an academic project, Mathematical Debate, which is an integrative part of the strategy and process of experiential learning is presented. The strategy of experiential learning is part of the perception of planning courses guided by a learning-focused approach, which emphasizes the formulation of learning outcomes. Planning a course in a learning-focused approach helps create dialogue between the academic faculty and students and leads to compatibility between the learning outcomes (course goals) and the teaching methods and goals of evaluation.
\end{abstract}

The purpose of this article is to present the need for paradigmatic change and the transition from planning a content-focused course to planning a course that is focused on learning and on the experience of learning. This article shall present a case study of a course in the "backward design" method, which is compatible with the learning-focused paradigm. The challenges posed by this method will be discussed as well.

Keywords: Experiential Learning; Mathematical Debate; Learning-Focused Approach

\section{INTRODUCTION}

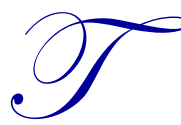

he internet has realized the vision of the global village through its innovative technology, and the information transmitted in the virtual space is diverse; for example, real-time news updates, reading newspapers from all over the world, ordering various services from home, playing online games with other users, and contacting other users on forums and in virtual communities (Barak \& King, 2000).

Academe, responsible for creating new information in modern society, has gone through a series of changes as well. Technological inventions such as the personal computer (Kulik, Kulik, \& Cohen, 1980), the world wide web (BrckaLorenz, Haeger, Nailos, \& Rabourn, 2013; Jones, 2002), the transition to distance learning (Phipps \& Merisotis, 1999), and the drastic rise in the number of academic students, are some of the factors behind these changes. Despite the transformations in the world of higher education, there have been only a few changes in learning strategies and instruction methods (Reynolds, 2000), despite the prevalent use and acceptance of new technologies (McKeachie, 1990). 
Notwithstanding the enormous change in the status and accessibility of knowledge, particularly among students of higher education who frequently use technology for learning (BrckaLorenz et al., 2013), teaching methods have remained static and still focus on the transfer of knowledge (Eberly, Newton, \& Wiggins, 2010). This fact is fairly problematic as the extensive use of technology in higher education does not necessarily contribute to learning or teaching (Kazley et al., 2013). Namely, the academic environment has indeed changed as a result of technology, but contemporary teaching methods (aside from effects facilitated by computers) have not.

Consequently, questions often arise concerning the value of academic degrees and the quality of learning in academic classrooms (Stage \& Muller, 1999), considering the constant focus on transferring knowledge. Many instructors still think that they can transfer their knowledge in a complete form to students' minds (Cross, 2000). This is not only impossible but, in the information era, it is an anachronistic approach that renders the instructor irrelevant. Students often ask themselves why they should make an effort to come to class when all the material appears on the course website or is freely accessible on the internet. Such questions indeed hint at the added value that instructors can give students beyond the transfer of knowledge.

Such questions are legitimate today more than ever and challenge the traditional paradigm of "teaching centered learning." Most people have been exposed throughout life to this approach that sees academic studies as a place where teaching is transferred through the study program (Barr \& Tagg, 1995). In a typical course, teaching is transferred and constructed according to the number of lessons (50-minute lectures and three credits), with the aim of covering the contents of the course and concluding with a final assignment that serves as a means of assessment (Reynold, 2000). In the traditional teaching method, "teachers decide for the learner what is required from outside by defining characteristics of instruction, curriculum, assessment, and management to achieve desired learning outcomes" (Wagner \& McCombs, 1995, p. 32).

As a result of the learner's passivity in traditional teaching, students are accountable for their learning process. They sit in their places, move from room to room and from course to course, play with their cellular phones, occasionally utter a comment in class, go on Facebook, and open and close their laptops. Eventually they complete the course (hopefully) with a little more knowledge, but no different than when they began. Students who learn in the traditional approach do not gain skills and, in this context, it has been said that acquiring a Bachelor's degree can be considered a hollow achievement if one has not acquired skills and capabilities suitable for the $21^{\text {st }}$ century in the process (Kuh, Kinzie, Schuh, \& Whitt, 2010, p. ix).

The purpose of the current article is to present a different approach to the teaching of mathematics while imparting applied tools for a transition from "teaching centered learning" to "learning-centered teaching."

\section{LEARNING-CENTERED TEACHING}

Learning-centered teaching is a new-old educational paradigm (Seel, 2003) that has its roots in the rise of the progressive education movement in the US in the late $19^{\text {th }}$ century. This approach is based on the principle that knowledge cannot be transferred to learners in its complete form, but rather by causing learners to discover or acquire knowledge independently (Rogoff, 1994). This is a shift from the traditional approach that sees learning as a process of passive knowledge reception from a figure of authority to a learning-centered approach that sees learning as an active process in which learners go through a process of change (Gehart, 2011). While in the traditional approach, the emphasis is on the scope and nature of contents learned and in the learning-centered approach, the emphasis is on the nature of the learner's process. According to this outlook, learning is a variety of activities and programs that challenge students and give them an opportunity to grow (King \& Anderson, 2004). Growth occurs when students undergo a series of changes that lead them to more complex behavior, enabling them to cope with changing life challenges (Kuh et al., 1991). This approach is based on the premise that what students do is more important that what they learn in their undergraduate studies (Kuh et al., 2010, p. 8).

The research literature shows that this approach indeed promotes higher quality learning. For example, a study examining the effect of learning-centered teaching versus instruction-centered teaching on the attitudes and knowledge of statistics, students (Harpe, Phipps, \& Alowayesh, 2012) found that those in the learning-centered approach were more knowledgeable and had more positive attitudes toward their learning environment. Students in 
the learning-centered approach reported having more opportunities to use their knowledge and feeling more in control of their grades. Nonetheless, despite the data supporting the learning-centered approach, most schools of higher education continue to treat information transfer as the most important value of teaching. Eberly, Newton, and Wiggins (2001) analyzed 145 syllabuses of various general undergraduate courses. Their thematic analysis found that $50 \%$ of syllabus themes dealt with administration (course format, course contents, and use of technology) and $75 \%$ of the themes emphasized course development (basic information about the course, reading requirements, course contents, methods of assessment, and use of technology). Only one theme in all the syllabuses examined dealt with the interpersonal realm (accountability for learning). The researchers concluded that the main emphasis in courses is on transferring information, while the topic of developing skills or attitudes as part of learning receives almost no attention. They claim that the syllabus, as a meaningful tool in the learning process, must reflect and formulate the goals of the degree as well as the goals of the course.

Table 1 is a portrayal of the learning paradigm that follows the emerging approach versus the instruction paradigm that follows the traditional approach (from Barr \& Tagg, 1995).

Table 1: Teaching and Learning Paradigms

\begin{tabular}{|c|c|}
\hline $\begin{array}{l}\text { The Learning Paradigm } \\
\end{array}$ & The Instruction Paradigm \\
\hline \multicolumn{2}{|l|}{ Mission and Purposes } \\
\hline Produce learning & Provide/deliver instruction \\
\hline Elicit students' discovery and construction of knowledge & Transfer knowledge from faculty to students \\
\hline Create powerful learning environments & Offer courses and programs \\
\hline Improve the quality of learning & Improve the quality of instruction \\
\hline Achieve success for diverse students & Achieve access for diverse students \\
\hline \multicolumn{2}{|l|}{ Criteria for Success } \\
\hline Learning and student-success outcomes & Inputs, resources \\
\hline Quality of exiting students & Quality of entering students \\
\hline Learning technologies development & Curriculum development, expansion \\
\hline Quantity and quality of outcomes & Quantity and quality of resources \\
\hline Aggregate learning growth, efficiency & Enrollment, revenue growth \\
\hline Quality of students, learning & Quality of faculty, instruction \\
\hline \multicolumn{2}{|l|}{ Teaching/Learning Structures } \\
\hline Holistic; whole prior to parts & Parts prior to whole \\
\hline Learning held constant, time varies & Time held constant, learning varies \\
\hline Learning environments & 50 minute lecture, 3 -unit course \\
\hline Environment ready when student is & Classes start/end at same time \\
\hline Whatever learning experience works & One teacher, one classroom \\
\hline Cross discipline / department & Independent disciplines / departments \\
\hline Specified learning results & Covering material \\
\hline External assessments of learning & End-of-course assessment \\
\hline Public assessment & Private assessment \\
\hline Degree equals demonstrated knowledge and skills & Degree equals accumulated credit hours \\
\hline \multicolumn{2}{|l|}{ Learning Theory } \\
\hline $\begin{array}{l}\text { Knowledge exists in each person's mind and is shaped by } \\
\text { individual experience }\end{array}$ & Knowledge exists "out there" \\
\hline Knowledge is constructed, created & $\begin{array}{l}\text { Knowledge comes in chunks and bits; delivered by } \\
\text { instructors, absorbed by students }\end{array}$ \\
\hline Learning is a nesting and interacting of frameworks & Leaning is cumulative and linear \\
\hline Learning is student centered and controlled & Learning is teacher centered and controlled \\
\hline $\begin{array}{l}\text { Learning environments and learning are cooperative and } \\
\text { supportive }\end{array}$ & The learning environment is competitive and individualistic \\
\hline
\end{tabular}

\section{ABOUT BACKWARD COURSE DESIGN}

Constructing courses in a backward design is based on the premise that teachers must clarify to students, unequivocally, what they are expected to learn, do, and understand by the end of the lecture or course. Backward course design forces instructors to move the focus of course design from course contents to outcomes. Such a design 
makes it possible for instructors to answer the questions often asked by students - "Why are we doing this assignment? What is its purpose and will I ever use it in real life?" (Daugherty, 2006). Backward design answers three questions:

1) What will the student know and be able to do, in general, by the end of the course, independent of the activities and texts used?

2) What evidence is there of such abilities?

3) Which texts, activities, and methods will best serve the desired results?

This approach originated from the scientific educational disciplines called STEM (Science, Technology, Engineering, and Mathematics) and derived from the endpoint; namely, what are the desired results and what outcomes do we expect of the course? (Wiggins \& McTighe, 2005). STEM disciplines were the first to embrace this approach and the purpose of the course became the starting point of course design (Streveler, Smith, \& Pilotte, 2012). Courses were planned in four stages and instructors were required to map desired outcomes, assessment methods, and teaching strategies as accurately as possible.

\section{AN EXAMPLE OF DEVELOPING A COURSE IN STAGES IN THE STEM DISCIPLINES}

\section{Stage A: Formulating Large Student-Centered Goals}

- What do you expect the graduate to know and be able to do?

- What do you expect the student to know and be able to do upon completing the course/unit (with regard to skills, knowledge, capabilities, perceptions, values)?

1. What is the big idea? What effect will this course have on a student's life by the end of the course? in a few years?

2. What are the practical expectations of course graduates?

- $\quad$ Ability to apply knowledge in mathematics, science, and engineering

- $\quad$ Ability to plan and conduct experiments

- $\quad$ Ability to analyze and interpret data

- Ability to plan a system, component, or process in a way that answers requirements with consideration of realistic constraints (financial, environmental, social, political, ethical constraints)

- $\quad$ Ability to function in multidisciplinary teams

- $\quad$ Ability to identify, formulate, and solve engineering problems

- $\quad$ Understanding of professional and ethical responsibility

- $\quad$ Ability to efficiently impart the wide education necessary in order to understand the effect of engineering solutions in the global, economic, environmental, and social context

- $\quad$ Recognition of the need and ability to engage in learning throughout life

- $\quad$ Knowledge of contemporary issues

- $\quad$ Ability to use modern engineering methods, capabilities, and tools essential for engineering work

\section{Stage B: Formulating Operative (Executive) Aims Resulting From the Large Goals}

The formulation shall take the form of three to five behavioral aims and shall list anticipated academic outcomes from the perspective of learners. For example, by the end of the course, the student shall be able to:

- $\quad$ Identify and solve numerical problems

- $\quad$ Choose the most appropriate numerical method for solving a problem according to its characteristics

- $\quad$ Understand the characteristics of the method and correctly interpret results 
Stage C: Choosing Assessment Methods (For Measuring Achievement of Teaching Goals) and Setting Criteria for Assessing Performance. How can Students Demonstrate That They Know and are Capable of Doing What is Expressed in the Goals?

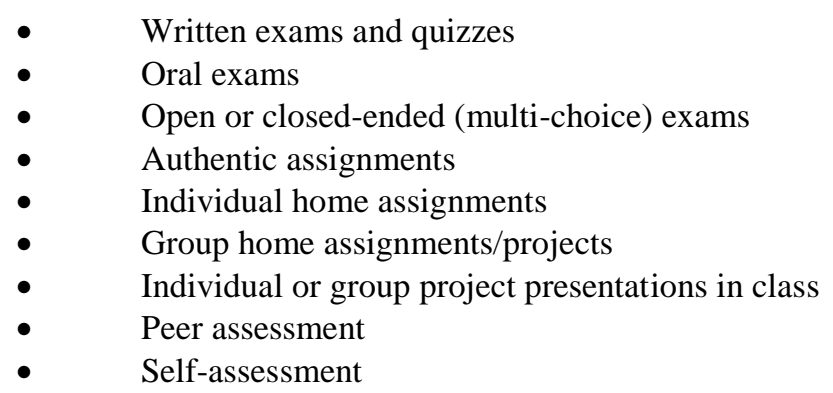

Stage D: Choosing Teaching Methods/Strategies for Achieving Aims: What Will you do in Your Teaching so That Students can Achieve the Aims you Formulated?

Format: Lectures, Seminar, Exercises and Laboratories/studios

Activities: Discussions, Demonstrations, Practice/coaching, Work in pairs/groups/collectively, Learning based on case studies/problem-solving, and Technology-supported learning.

In each method, secondary aims should be listed as well as practical learning experiences that will be included in each teaching method. For example, if the goal of instruction is to help students develop skills, both in teamwork and in individual work, through teaching and learning methods, teaching methods for achieving the secondary aims of this goal will be:

- In order to learn how to work in a team, teamwork is essential.

- In order to learn to communicate, assignments on communication problems should be given.

- In order to learn to be accountable for their learning, students will be required to learn on their own how to solve assignments.

- In order to learn ethical, social, professional, and environmental aspects related to the discipline, appropriate examples for demonstration or discussion should be included.

\section{Stage E: Other Aspects}

- What special activities are you planning for the first week of the course?

- How will you inform students of the course program?

- What problems might arise in planning and holding the course?

- How will you deal with these problems?

- How will you assess your success in achieving the aims of the course?

- How will you assess your teaching in the course?

This method of course design helps develop students' deep knowledge contents. This approach makes it possible for students to improve their ability to search for and find information and contributes to the development of metacognitive abilities (Thompson \& Licklider, 2011). Although students don't always understand how and why they should be accountable for their learning (Wiersema \& Licklider, 2007) and are not necessarily inherently capable of extensive learning beyond acquiring knowledge (Wiersema \& Licklider, 2007), the purpose of backward design is to urge students to maximize their abilities and cause them to relinquish the position of passive recipients of knowledge.

The backward design approach is applied in the US, mainly in STEM disciplines, as a result of the covert/overt assumption of policymakers that the scientific field is most worthy of educational investment as 
economic success is dependent on it. Indeed, the significance of STEM disciplines cannot be denied; however, the question is whether these fields are superior to others - for example, the humanities. The authors think not. It is necessary to strive for effective learning outcomes, not only in the STEM disciplines, but in all academic disciplines.

\section{ABOUT EXPERIENTIAL LEARNING AND ITS IMPLICATIONS}

Experiential learning can be divided in two: 1) learning experienced personally in daily life and through one's life events and 2) learning by means of programs devised by others. For the latter, there is need for advance preparation and working through the process at its conclusion.

Carver (1996) proposed a model of experiential learning with four features - active learning, assimilating the experience through cognitive and emotional work on materials, authenticity of the study matter (relevance for learners), and providing means of creating related experiences. The theory contends that integrating these features in the learning process might make it significantly more meaningful and help sustain the experience over time (Bacon \& Kimball, 1989).

The theoretical model of experiential learning presents learning as a five-stage process - a learningexperiential occurrence, sharing, processing, generalization, and application. According to the model, learning as an active experience lets learners use knowledge in a practical applied manner and develops their life skills (Pfeiffer \& Jones, 1983).

Imparting knowledge and developing life skills are the equivalent of expanding and improving one's cognitive dimensions. Cognitive models allege that one's concept of self and of the world is organized in a complex manner, as a result of a unique cognitive alignment. The cognitive alignment and arrangement of information affect one's worldviews, inclinations, responses, and adaptation (Walter \& Marks, 1981).

\section{MATHEMATICAL DEBATE - A LEARNING EXPERIENCE}

This study shall focus on a case study of a project constituting a learning experience in mathematics - the "mathematical debate" (Williams Klima, 2011) first initiated in the 1970s at schools for the gifted in Moscow and St. Petersburg, Russia (Gendin, Itenberg, \& Fomin, 1994). Its first version was a mathematical competition named "mathematical battle" and it differed significantly from all previous competitions. This competition had several new principles (Fedotov, 1972):

1. It is a group competition (a group of participants submits a single joint solution).

2. Participants not only solve high-level mathematical problems but must also present the solution in public, defend it, and justify it before the audience and representatives of the others groups.

3. A major part of the competition is to get to know the solutions of the other participants and to criticize them.

The activity takes part in two stages. In the first stage, participants split up into groups. Every group receives a collection of problems (all groups receive the same collection) which the group is required to solve in a given time frame. In the second stage, the group presents its solutions. Each group invites the other to present a solution to a certain problem. The group's representative describes its solution to the audience; then representatives of the other groups review the solution and check it for correctness, accuracy, and completeness. Reviewers can ask questions during the presentation of the solution and they can also request additional explanations.

The idea became extremely popular among schools for the gifted and extra-curricular mathematics classes, particularly due to the experiential aspects of the activity. From the moment the problem is received, the intellectualvalent-emotional experience begins - distributing the problems among members of the group, presenting and reviewing the solution within the group, group improvement of the solution, and selecting the representative for each of the problems for the public stage. The public stage is an act with a strategy and logistics of its own (selecting the problems for which the group wishes to present solutions and the problems that it prefers to review, and selecting representatives for each of the problems). The solution presentation part is like a "show," with the outcome 
dependent both on the ability of the representatives to explain the solution clearly and persuasively and to cope with the review - and on the reviewer's ability to explore the solution voiced, to pay attention to every detail of the proof, to ask matter-of-fact and convincing questions. If this entire program also has a good conductor (teacher or someone who organizes the activity) and the preparation is serious, then the experience is unforgettable.

However, despite the popularity of "mathematical battles," until recently this activity was utilized only with gifted students and the main emphasis was on the competitive factor rather than on the academic factor.

\section{CASE STUDY: A NEW OPTION IN THE EXPERIENTIAL LEARNING APPROACH - MATHEMATICAL DEBATE}

In 2013, a new idea was formulated at Ariel University using the "mathematical battle" format for learning purposes, with the aim of posing an intellectual, emotional, and value-laden challenge to academic learning. Three research directions were determined:

1. The possibility of using this activity as an integrative part of the learning process

2. The possibility of using the activity among high school students on all levels (particularly important would be experiential learning for students considered weak in mathematics)

3. Use of the activity to teach academic students (to date there has not been much experience with experiential learning among adults).

The "mathematical debate" changed the emphasis from the competitive ("battle") to the learning ("debate" - math speech). For this purpose, several different forms of the activity were developed as determined by academic needs.

The main idea of the "mathematical debate" is the focus on the solution process, understanding all stages of the solution, and understanding the mathematical concepts and sentences used rather than rapid acceptance of the result. Every solution is reviewed several times:

1. When a student or group of students solve the problem. Since the student knows that he will have to present the solution to members of the group and defend it, he asks himself, "Have I missed anything? Did I use the terms and rules appropriately?"

2. At the stage of preparing the group solution, the whole group takes part in the review. At this stage, questions about the problem are prepared for the other groups as well. This process helps enhance understanding.

3. At the public stage, when all participants discuss the problem, what one group missed will be stressed by another and what seemed trivial now arouses doubts.

Obviously, in order for the activity to be beneficial, there is need for deep precise understanding of all stages of the activity and, first and foremost, to select assignments that fit the goals of the activity. In contrast to the "mathematical battle" competitions, whose main purpose was the competition and therefore the primary criterion for selecting the problems was their level of difficulty, every problem in the "mathematical debate" has a didactic or methodical purpose. For example, problems are chosen based on analysis of common mistakes uncovered by tests of the group. The time span for the activity is chosen according to its purpose - from a "mini-debate" in class (15 minutes for group solution and discussion and 15 minutes for public discussion) aimed at discussing a single problem or problematic term - to an activity that can even be an entire day devoted to mathematics at the faculty or school. In this case, the participants are different study groups, the quantity of material on which the problems are based is much greater, and the material is more diverse. In regard to the learning outcomes, there are also interesting options of organizing activities between different age groups learning the same material on different turns of the "knowledge spiral" (for example, tenth graders learning geometry and eleventh graders reviewing the material for the matriculation exam). 


\section{VARIOUS POSSIBILITIES FOR STUDENT ACTIVITY}

Analysis of a questionnaire administered to students on their attitude to various study methods showed that some students do not feel comfortable with group work. This led the authors to the idea that the "mathematical debate" gives each student a variety of opportunities and roles. For example, one group of students may help compose problems. These students will "enjoy" the discussion as a form of study but at a different stage of the activity. Students can also serve as judges. The responsibility encompassed in this role can bring a weak or "uncaring" student to learn about the subject of the activity in order to avoid social "embarrassment." In one "debate," a student decided that she wished to be in "a group of her own." She tried to solve all the problems alone and then was also a representative, saw the solutions, and reviewed the solutions of other groups in the public stage. She achieved a good result, but, interestingly, the next time around, she decided to join one of the other groups of her own free will.

Furthermore, in the "mathematical battle" competition, as in any other competition, there are written rules that are binding for all organizers and participants. In contrast, the rules of the debate activity are flexible, based on the principle that the activity itself is part of the learning process and it is important for the experience to be positive and beneficial.

\section{CRITERIA FOR SELECTING ASSIGNMENTS}

The main part of organizing the activity is problem selection, which is common to all types of "mathematical debate"; formulation of the problem and its manner of solution should facilitate and invite discussion. From discussion on a very simple level, for example, students find it hard to identify trigonometric functions and their correct use in solving geometric problems. Several such problems in the class "mathematical debate" will arouse intra-group and inter-group discussions and will also help students see the problem "from the side" (in a student survey, most stressed that when checking the work done by peers, they learn about their own mistakes).

The type of problems that invite discussion include those that can be solved in many ways, those that can be solved incorrectly if not thought through sufficiently, or those that include a stage that seems natural but the explanation is not trivial (this happens a lot, for instance, with support constructions).

\section{EXAMPLES}

Several examples of the selection of problems for a "mathematical debate" will now be presented, while explaining the rationale for their selection.

\section{Assignment 1}

The first example is from the field of solid geometry. Experience in teaching indicates that in solid geometry it is most difficult to teach how to build angles in space (between two planes or between a straight line and a plane). In order to make it less problematic and to help students understand the definitions, after a few lessons in solid geometry the authors attempted to organize a "mini debate" on the subject. The students were divided into groups and assigned the following problem (Figure 1), given a quadrangular prism $A B C D A{ }^{\prime}{ }^{\prime} C^{\prime} D$ ' whose base is a trapezoid:

What is the angle between the planes $\mathrm{A}^{\prime} \mathrm{B}^{\prime} \mathrm{C}^{\prime}$ and $\mathrm{CD}^{\prime} \mathrm{D}$ ? 


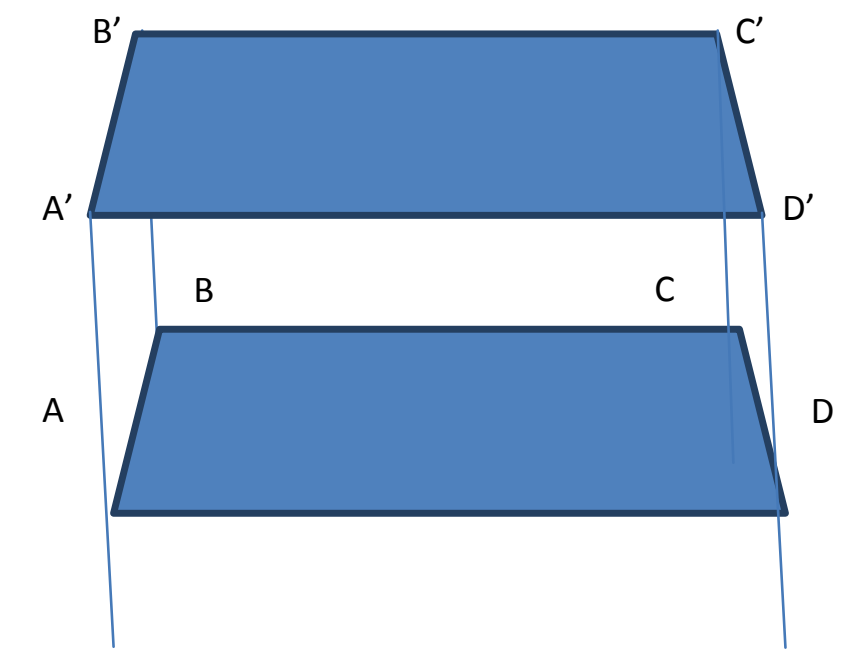

Figure 1: Problem Presented to Student Groups (Assignment 1)

The students were given no time limit but, very quickly, all groups announced that they were ready to present the solution. The representative of the first group said that it was the angle between the side face of the prism $C^{\prime} D^{\prime} D$ and the upper base $A^{\prime} B^{\prime} C^{\prime} D^{\prime}$, but the reviewer from the second group asked for an explanation of "why does point $\mathrm{D}^{\prime}$ belong to plane $\mathrm{A}^{\prime} \mathrm{B}^{\prime} \mathrm{C}^{\prime}$ and point $\mathrm{C}^{\prime}$ to plane CD'D?" The answer - "but it's obvious!" - did not pacify him. He was also unwilling to accept the claim that all four points are on a certain plane and even disproved it. When it became clear that the representative of the first group had no relevant explanation, the reviewer brought an accurate proof. All the groups agreed that the angle between the given planes equals 90 degrees, but there was an argument about the precise angle called "the angle between the given planes". The representative of the first group stated that the angle is $\mathrm{B}^{\prime} \mathrm{C}^{\prime} \mathrm{C}$. This is indeed a right angle and it is formed by straight lines, each of which belongs to the given planes, but one of the reviewers did not agree. He explained that the line intersecting the planes is C'D'. Although in the plane $\mathrm{CD}^{\prime} \mathrm{D}$ the straight line $\mathrm{CC}^{\prime}$ is perpendicular to $\mathrm{C}^{\prime} \mathrm{D}^{\prime}$; the trapezoid must be right-angled in order for $\mathrm{B}^{\prime} \mathrm{C}^{\prime}$, in the plane $\mathrm{A}^{\prime} \mathrm{B} \mathrm{C}^{\prime}$, to be parallel to the intersecting line, but this is not given. Therefore, the angle $\mathrm{B}^{\prime} \mathrm{C}^{\prime} \mathrm{C}$ does not fit the definition of an angle between two planes.

The other group suggested drawing a diagonal $\mathrm{A}^{\prime} \mathrm{C}^{\prime}$ and then the requested angle is angle $\mathrm{A}^{\prime} \mathrm{C}^{\prime} \mathrm{C}$, but this version was also rejected by the reviewer - the diagonal is not necessarily perpendicular to the side of the trapezoid. The discussion ended when one of the groups suggested a correct algorithm for constructing the angle and everyone agreed.

The benefit of the activity was not only that the students learned how the angle should be constructed, but also that they encountered and discussed mistakes that could occur when constructing the angle as well as how to prevent them. Further on in the activity, all of the groups were asked to devise and ask a question related to the given problem. The question devised by one of the groups was, "Which qualities should the trapezoid at the base of the prism have so that there will be no need for support constructions in order to define this angle?" This question was a direct result of the discussion which indicated that it was not in vain.

\section{Assignment 2}

The other example is from a "mathematical debate" aimed at helping first-semester students review for an exam in calculus. The main topic of the exam was continuous functions. The task was to examine the continuity and to draw graphs of the following functions:

$$
\begin{array}{ll}
\text { 1. } & \mathrm{F}(\mathrm{x})=[\mathrm{x}] \\
\text { 2. } & \mathrm{F}(\mathrm{x})=\mathrm{x}-[\mathrm{x}] \\
\text { 3. } & \mathrm{F}(\mathrm{x})=[\mathrm{x}]+(\mathrm{x}-[\mathrm{x}])^{\wedge} 1 / 2
\end{array}
$$


Most of the students easily answered the first question because this is the example usually used to describe discontinuity. Interestingly, already in this question the groups had different approaches to proving the discontinuity.

The student whose group was supposed to present the solution said:

We know that the whole value of all numbers from zero to one equals zero, the complete value of all numbers from one to two is one, and so on. That is why the graph jumps and here is the drawing:

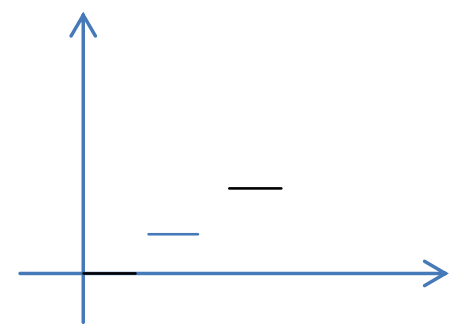

However, this solution was strongly criticized by the reviewer. He claimed, first of all, that this is not proof but rather only several examples that represent the group's hypothesis. Additionally, he also did not agree with the graph's description (it lacks reference to the $\mathrm{X}<0$ range and uncertainty in "whole" points). Some students insisted that the graph was correct because "that's what we learned." It was important to hear that it is certainly possible that the lecturer "simplified" the matter to such a degree that he indeed used a partial form of the graph of whole values. Here the authors would like to emphasize the ability of their method to provide an "inverse relationship"; i.e., to give the teacher the opportunity to hear and see exactly what the students understood based on what was said in the lecture. The reviewer drew an accurate graph and also brought an analytical proof of the function's discontinuity and that of a type of discontinuity. The representative of the first group understood the idea and his answer to the second function was perfect (including an analytical proof and accurate graph). Learning from peers is a central part of the activity. The game experience (desire to earn points for the group, to present the group well, encouragement of friends) increases the student's concentration, rapid thought, and perception. In regard to the third function, the first group had no answer. The reviewing group did not have a full answer, but their representative estimated that this function also has a jump-type discontinuity at every "whole" point because it is a combination of the two previous functions. The representative of the first group was doubtful, asking, "Which sentences are there on combinations of continuous functions?" He knew that adding two continuous functions would give a continuous function, but he was not certain about roots. Nonetheless, the answer seemed logical to him and he was willing to accept it; but he requested an analytical proof. The representative of the second group was capable of producing an analytical proof, but when preparing the group solution, the group did not think it was necessary because they thought that the answer derives from the two previous functions. The argument "forced" the representatives to take the analytical course and, to their surprise, they found that the function is continuous in the entire range. The representative of the third group, which did not take part in the discussion on this question, even managed to draw the graph.

\section{Additional Assignments}

A special experience with a considerable effect on students' comprehension is the "mathematical debate" on "true/false" questions. Here, even when everyone has a correct answer, the contrasting examples in "false" cases can vary significantly and the reviewer must understand and accept or refute the example. It is also interesting to develop a discussion on a proof known to be mistaken (for example, the famous proof that all triangles are equilateral) with the purpose of understanding and explaining the logical mistake or mistakes.

\section{Effect of the Activity}

The authors noticed that students' participation in "mathematical debates" changes their attitude to the discipline on several dimensions:

1. The experiential aspect of the lessons makes them desirable. Before class, students often ask what type of activity they will have today. 
2. From a certain stage, students themselves begin to notice problems with a debate potential. They often bring questions that they think are good material for a "debate."

3. The students start talking about math, both in class and elsewhere. They become interested not only in the correct answer, but also in ways of solving the problem. Students ask each other whether they noticed all the possibilities, whether the constructions were legal, etc. In this way, math studies become experiential elsewhere as well.

4. Students ask many more questions about new material as well as phenomena they noticed when preparing homework. Most of the questions are interesting and sometimes spark an unplanned "debate."

5. Math studies, where the student finds himself in an active role (in contrast to the "hearing - doing" of a regular class), become habitual and, in the authors' opinions, raise the quality of studies.

\section{DISCUSSION AND CONCLUSION}

The unique role of the backward design instruction method begins with identification of the learning goals of the course rather than with the course material and contents. In order to identify goals, instructors must ask themselves, "What must students know and be able to do by the end of the course?" They must choose assessment methods and criteria for measuring implementation. According to these goals, a teaching method is chosen. Instructors must choose the best teaching method in order to achieve the learning goals, both regarding the material to be included in the course and regarding the instruction strategy, planning of the schedule, and syllabus design. Expanding use of the backward design approach to all academic disciplines shall enable students to personally benefit from an array of courses rather than only STEM courses. If course design will remain content-centered, many disciplines will probably become irrelevant as students will continue to leave as they arrived.

With the increase in accessible knowledge, instructors are required to bring with them added value. This is a complicated requirement that compels instructors to think "outside the box" - to relinquish regular teaching patterns. From the authors' experiences with backward design, planning a course in this method undoubtedly requires extensive thinking, time, and effort, compared to designing a course in the traditional method. It is necessary to become acquainted with students, be prepared for changes, and plan well for each lesson. In backward design, there is no room for spontaneity. An instructor cannot come to class without self-examination of the goals and means to be used. This requires a big effort; however, such an effort makes it possible for the instructor to face students with a real honest answer to questions such as, "How will this help me in life?" or "Why should I come to class?"

Nevertheless, the instructor's efforts are not enough. In order for deep meaningful change to occur in instructor's form of teaching in academe, this must be reinforced by policymakers. In an academic environment where instructors' output equals the number of their scientific publications (research output), instructors have no incentive to make an effort and develop their teaching. The Council for Higher Education (CHE) also recognizes the significance of incentives versus teaching outcomes. In the council's budgeting model, teaching output relates to the number of undergraduate and graduate students in the school and the level of degrees awarded, calculated in an efficiency formula (Council for Higher Education, 2012). Despite the change in the budgeting model employed by the CHE, it is doubtful whether this can overcome the superior status of the research component and make faculty see efficient teaching as a type of academic output as well. For this purpose, there is need for a model that recognizes and appreciates learning-centered teaching - one that will enable instructors to devote time and energy to developing these aspects of their work.

The question remains whether, in the current state of affairs with the loaded curriculum (both of academic and of high school students) and the limited number of teaching hours, it is possible to devote part of the time to experiential activities or whether such activities should remain outside the formal school system (extra-curricular classes, math days, etc.). Will the experiential classes not result in a delay in studying the required material? Based on the authors' experiences, the activity has the added benefit of enhancing knowledge and understanding of the material, active learning, and involvement of students in the learning process, eventually helping students deal with the loaded curriculum and facilitating success in exams that require intensive understanding of the material and readiness to handle nonstandard problems. 


\section{AUTHOR INFORMATION}

Dr. Nitza Davidovich currently serves in teaching and administrative positions at Ariel University and is Director of Academic Development \& Evaluation. Areas of interest include academic curriculum development; development of academic instruction, Holocaust awareness and Jewish identity, student exchange programs with Germany and Poland, preservation of the heritage of Jewish sects, and moral education. Academic administration: Leader of academic assessment process at the Ariel University on behalf of the CHE, initiation and development of national and international academic collaboration, curriculum development and development of curricula for special-needs populations. E-mail: $\underline{\text { d.nitza @ ariel.ac.il }}$

Dr. Roman Yavich specializes in informatics and deals with the use of the Internet technologies in the educational process. Dr. Yavich is the author of the technical support concept in the Internet MathOlympiad organization, is responsible for Computing Systems Support of the Faculty of Natural Sciences at Ariel University, and he is a member of the Steering Committee of the Israel Mathematical Olympiad (on behalf of the Ministry of Education). Areas of interest include Distance Education, ELearning, Networked Learning, Technology Education, Pedagogy. Academic administration: Referent of e-learning-Professional consultation for all Faculties and Departments in the field of E-learning, developing computer-based training software, and computer use in teaching process improvement. E-mail: romany@ ariel.ac.il (Corresponding author)

Ms. Nelly Keller received her M.A. degrees in Applied Mathematics and in Sociology from the University of Perm, Russia, in 1981. For more than 30 years, she has worked as a Mathematics teacher in high schools in Russia and Israel. Since 2007, she is a lecturer in the Center for pre-University education at the Technion (Israel Institute of Technology) and she recently enrolled into a Ph.D. program in the Ariel University, Israel. Ms. Keller is involved in numerous projects in the field of Mathematical education and, in 2012, she received the Avital Prize for innovation and creativity in Mathematics teaching.

\section{REFERENCES}

1. $\quad$ Bacon, S. B., \& Kimball, R. (1989). The wilderness challenge model. In R. Lyman, S. Prentice-Dunn, \& S. Gabel (Eds.), Residential and inpatient treatment of children and adolescents. New York: Plenum Press.

2. Barak, A., \& King, S. A. (2000). The two faces of the Internet: Introduction to the special issue on the internet and sexuality. Cyber Psychology \& Behavior, 3, 517-520.

3. BrckaLorenz, A., Haeger, H., Nailos, J., \& Rabourn, K. (2013). Student perspectives on the importance and use of technology in learning. Paper presented at the Annual Forum of the Association for Institutional

Research. Retrieved on May 31 from: http://nsse.iub.edu/html/pubs.cfm?action=\&viewwhat= Conference\%20Paper,Conference\%20Presentation

4. Barr, R. B., \& Tagg. J. (1995). From teaching to learning. Change, 27, 13-25.

5. Cross, K. P. (2000). Cross paper \#4: Collaborative learning 101. Mission Viejo, CA: League for Innovation in the Community College.

6. Carver, R. (1996). Theory for practice: A framework for thinking about experiential education. The Journal of Experiential Education, 19, 8-13.

7. Daugherty, K. K. (2006). Backward course design: Making the end the beginning. American Journal of Pharmaceutical Education, 70, 1-5.

8. Eberly, M. B., Newton, S. E., \& Wiggins, R. A. (2001). The syllabus as a tool for student-centered learning. The Journal of General Education, 50, 56-74.

9. Gehart, D. (2011). The core competencies and MFT education: Practical aspects of transitioning to a learning-centered, outcome-based pedagogy. Journal of Marital and Family Therapy, 37, 344-354.

10. Harpe, S. E., Phipps, L. B., \& Alowayesh, M. S. (2012). Effects of a learning-centered approach to assessment on students' attitudes towards and knowledge of statistics. Currents in Pharmacy Teaching and Learning, 4, 247-255.

11. Jones, S. (2002). The Internet goes to college: How students are living in the future with today's technology. 
12. Kazley, A. S., Annan, D. L., Carson, N. E., Freeland, M., Hodge, A. B., Seif, G.A., \& Zoller, J. S. (2013). Understanding the use of educational technology among faculty, staff, and students at a medical university. TechTrends, 57, 63-70.

13. King, J. M., \& Anderson, D. M. (2004). A practitioner's guide to a learning-centered co-curricular activities orogram. College Student Affairs Journal, 24, 91-100.

14. Kuh, G. D., Kinzie, J., Schuh, J. H., \& Whitt, E. J. (2010). Student success in college: Creating conditions that matter. Jossey-Bass.

15. Kuh, G. D., Schuh, J., Whitt, E., Andreas, R. E., Lyons, J. W., \& Strange, C. C. (1991). Involving colleges. Successful approaches to fostering student learning and development outside the classroom. San Francisco: Jossey-Bass.

16. Kulik, J. A., Kulik, C.-L. C., \& Cohen, P. (1980). Effectiveness of computer-based college teaching: A meta-analysis of findings. Review of Educational Research, 50, 525-544.

17. Neill, J. T. (2003). Reviewing and benchmarking adventure therapy outcomes: Applications of metaanalysis. Journal of Experiential Education, 25, 316-321.

18. Phipps, R., \& Merisotis, J. (1999). What's the difference? A review of contemporary research on the effectiveness of distance learning in higher education. Institute for Higher Education Policy, Washington, DC.

19. Pfeiffer, J. W., \& Jones, J. E. (1983). Reference guide to handbooks and annuals. John Wiley \& Sons, Inc.

20. Reynolds, J. (2000). Learning-centered learning: Theory into practice. Inquiry, 5, 1-9.

21. Rogoff, B. (1994). Developing understanding of the idea of communities of learners. Mind, Culture, and Activity, 1, 209-229.

22. Rosol, M. (2000).Wilderness therapy for youth-at-risk. Parks and Recreation, 35, 42-9.

23. Russell, K. C. (2000).Exploring how the wilderness therapy process relates to outcomes. Journal of Experiential Education, 23, 170-176.

24. Stage, F. K., \& Muller, P. (1998). Creating learning-centered classrooms. What does learning theory have to say? ERIC Digest. Retrieved on May 30 ${ }^{\text {th }}, 2013$ from: http://www.ydae.purdue.edu/lct/hbcu/documents/ Creating_Learning_Centered_Classrooms_What_Does_Theory_Say.pdf

25. Seel, N. M. (2003). Model-centered learning and instruction. Technology, Instruction, Cognition and Learning, 1, 59-85.

26. Thompson, J. R., \& Licklider, B. L. (2011). Visualizing urban forestry: Using concept maps to assess student performance in a learning-centered classroom. Journal of Forestry, 109, 402-408.

27. Walter, G., \& Marks, S. (1981). Experiential learning and change: Theory design and practice. New York: J. Wiley publication.

28. Wagner, E. B., \& McCombs, B. L. (1995). Learner centered psychological principles in practice: Designs for distance education. Educational Technology, 35, 32-35.

29. Wiersema, J. A., \& Licklider, B. L. (2007). Accountability for learning belongs to the learner. Higher Education in Review, 4, 43-61.

30. Wiggins, G., \& McTighe, J. (2005). Understanding by design: Expanded second edition. Alexandria, VA: ASCD.

31. Williams Klima, V. (2011). A different sort of calculus debates, mathematical time capsules: Historical modules for the mathematics classroom.

32. Генкин С.А.,Итенберг И.В., Фомин Д.В. Ленинградские математические кружки. Киров, Аса,1994,с 272.

33. Федотов В.П. Квант № 10, 1972, Издательство " Наука".

34. Davidovich, N., Yavich, R., \& Domoshnitsky, A. (2012). Mathematical games: International Mathematics olympiad for students. Far East Journal of Mathematical Education, 9(2), 133-140.

35. Domoshnitsky, A., Yavich, R., Bugaenko, V., Kannel-Belov, A. (2012). International mathematical internet olympiad. Journal of Systemics, Cybernetics and Informatics, 10(5), 50-54.

36. Domoshnitsky, A., \& Yavich, R. (2011). Internet Mathematical olympiad for students, mathematics competitions. Journal of the World Federation of National Mathematics Competitions Organizers, AMT Publishing, 24(1), 11-21.

37. Domoshnitsky, A., \& Yavich, R. (2009). Mathematical competitions for university students. Proceedings of the 10th International Conference Models in Developing Mathematics Education, Dresden, Saxony, Germany, 143-145. 
38. Domoshnitsky, A., \& Yavich, R. (2009). Internet mathematical olympiads. Proceedings of the 10th International Conference Models in Developing Mathematics Education, Dresden, Saxony, Germany. 